\title{
STRUCTURE OF THE FEMALE CEPHALIC END AND CUTICULAR ORNAMENTATIONS OF PARAPHILOMETROIDES NEMIPTERI (NEMATODA: PHILOMETRIDAE), AS REVEALED BY SEM
}

\author{
František Moravec
}

Institute of Parasitology, Biology Centre of the Academy of Sciences of the Czech Republic, Branišovská 31, 37005 České Budějovice, Czech Republic

\begin{abstract}
Scanning electron microscopy (SEM) examination of a paratype specimen (gravid female) of the philometrid nematode Paraphilometroides nemipteri Moravec et Shaharom-Harrison, 1989, the type species of Paraphilometroides Moravec et Shaharom-Harrison, 1989, made it possible to recognise the true structure of the cephalic end and the shape of cuticular ornamentations on the body. In contrast to other philometrid genera, the cephalic end is angular in lateral view and rounded in dorsoventral view; large external cephalic papillae are fused together to form a marked dorsal and a ventral ala, each bent into a curve; six minute internal papillae, including a pair of previously not reported lateral papillae, were found; amphids were indistinct. Cuticular ornamentations (inflations) were found to be transversely elongated. These features, especially the unique cephalic structure, clearly distinguish Paraphilometroides from other philometrids and confirm the validity of this genus.
\end{abstract}

Moravec and Shaharom-Harrison (1989) erected the hitherto monotypic philometrid genus Paraphilometroides Moravec et Shaharom-Harrison, 1989 with the type species $P$. nemipteri Moravec et Shaharom-Harrison, 1989, described from females found in the fins and operculum of the marine fish (notchedfin threadfin bream) Nemipterus peronii (Valenciennes) from off the South China Sea coast, Malaysia. The male of $P$. nemipteri remains unknown.

The authors distinguished Paraphilometroides from the related genus Philometroides Yamaguti, 1935 mainly by the unusual structure of the female cephalic end, which is unique within the family Philometridae (see Moravec 2006). However, P. nemipteri was studied only by light microscopy (LM), whereas some details of the cephalic structure, especially the cephalic papillae of gravid philometrid females are usually difficult to observe by LM due to a various degree of their reduction and atrophy (Moravec 2004); in the past, some philometrid species were even reported to have no cephalic papillae. Consequently, the only reliable method to study the cephalic structures in philometrids is the use of scanning electron microscopy (SEM).

Therefore, one of the ethanol-preserved paratype specimens (gravid female) of P. nemipteri, deposited in the Helminthological Collection of the Institute of Parasitology, Biology Centre of the Academy of Sciences of the Czech Republic in České Budějovice (Cat. No. N-372), was used for SEM examination. This was transferred to $4 \%$ formaldehyde solution and then refixed in $1 \%$ osmium tetroxide, dehydrated through a graded acetone series, critical point dried and sputter-coated with gold; it was examined using a JEOL JSM-7401F scanning electron microscope at an accelerating voltage of $3 \mathrm{kV}$ GB low.

Moravec and Shaharom-Harrison (1989) reported that the dorsal and ventral sides of the cephalic end of $P$. nemipteri were provided with a wide "cuticular ala" bent into a curve, each supported by the inner muscular layer; they illustrated eight large cephalic papillae of the external circle to form four submedian pairs located outside the alae and they observed only four pairs of small submedian papillae of the internal circle. The present SEM study confirms the existence of cephalic alae in this species (Fig. 1 A-D), however, these are not only "cuticular" but formed by flat, fused-together external cephalic papillae; these papillae are still slightly outlined in the alae (Fig. 1 B). In contrast to the original description, the small internal cephalic papillae are six in number in this species (a pair of lateral papillae was overlooked), as in most philometrids, and all cuticular ornamentations on the body were found to be transverse oval in apical view (Fig. 1 E). Amphids were indistinct by SEM.

Eight flat, large external cephalic papillae arranged in transverse dorsal and ventral rows have been reported in Philometra beninensis Obiekezie, 1986, a subcutaneous parasite of marine fish (Obiekezie and Anders 1991). However, in contrast to P. nemipteri, its papillae are not fused together to form the ala bent into a curve, but they are distinctly separated from each other. Since the cephalic structure of Paraphilometroides is very unusual and does not occur in other hitherto described philometrids, this genus should be considered valid.

The author's thanks are due to the Laboratory of Electron Microscopy, Institute of Parasitology, Biology Centre of the ASCR, České Budějovice for technical assistance and Blanka Škoríková, Department of Helminthology at the same Institute, for help with illustrations. This study was supported by research projects of the Institute of Parasitology, BC ASCR (Z60220518 and LC522). 


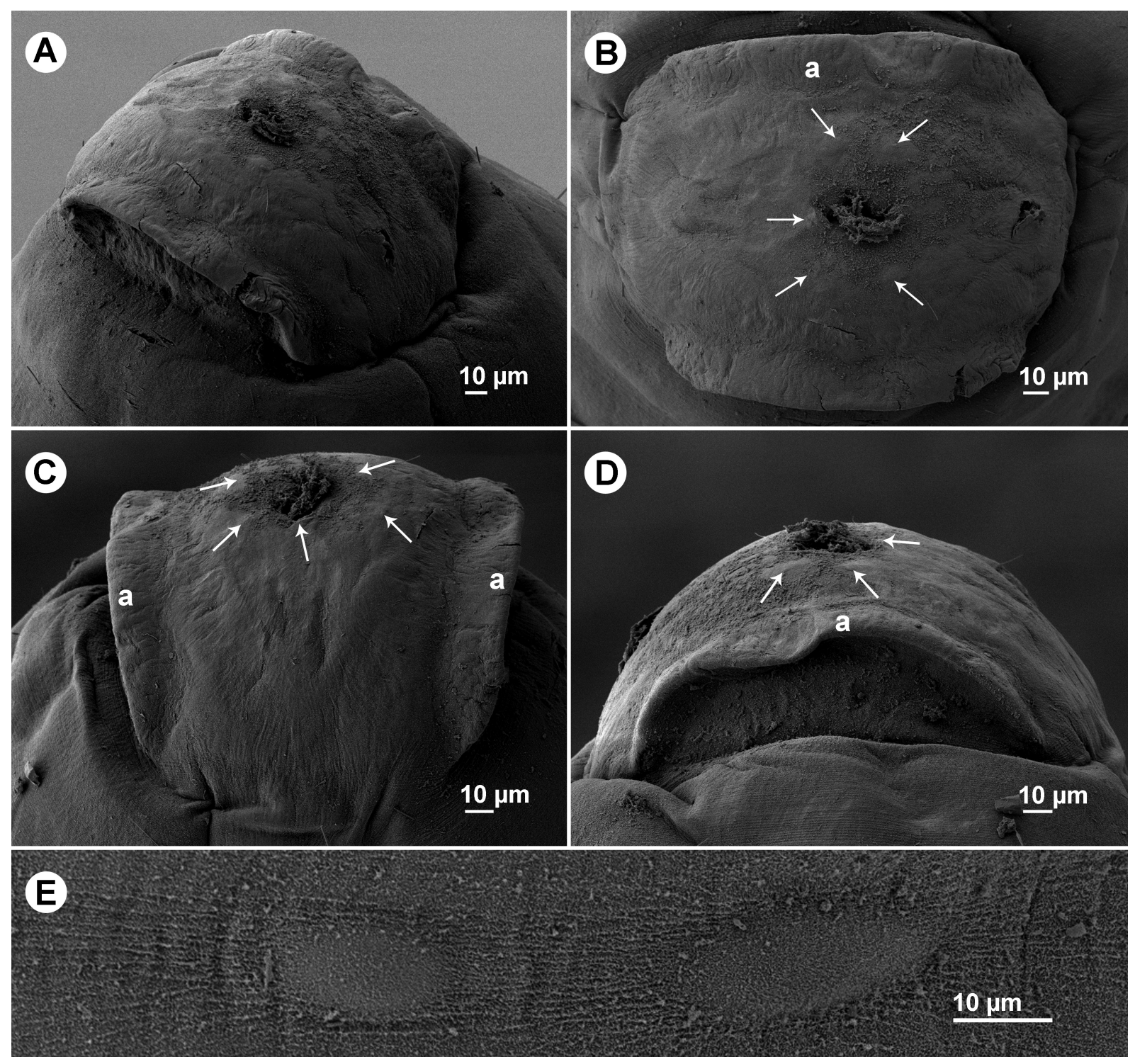

Fig. 1. Paraphilometroides nemipteri Moravec et Shaharom-Harrison, 1989, scanning electron micrographs of paratype gravid female. A, B - cephalic end, dorsolateral and apical views (arrows indicate cephalic papillae of internal circle); $\mathbf{C}, \mathbf{D}$ - cephalic end, lateral and dorsoventral views (arrows indicate cephalic papillae of internal circle); $\mathbf{E}$ - two cuticular excrescences at middle part of body, apical view. Abbreviation: a - cephalic ala formed by modified and fused-together papillae of external circle.

\section{References}

Moravec F. 2004: Some aspects of the taxonomy and biology of dracunculoid nematodes parasitic in fishes: a review. Folia Parasitol. 51: 1-13.

Moravec F. 2006: Dracunculoid and Anguillicoloid Nematodes Parasitic in Vertebrates. Academia, Prague, 634 pp.

Moravec F., Shaharom-Harrison F. 1989: Paraphilometroides nemipteri gen. et sp. n. (Nematoda: Philometridae) from the marine fish Nemipterus peronii (Valenciennes) from Malaysia. Folia Parasitol. 36: 345-350.

Obiekezie A.I., Anders K. 1991: Scanning electron microscope studies on Philometra (Ranjhinema) beninensis Obiekezie, 1986 (Nematoda: Philometridae). Folia Parasitol. 38: 371-374.

Received 15 January 2010

Accepted 27 January 2010 